\title{
Configurações
}

Revista de sociologia

$25 \mid 2020$

Debater o desenvolvimento: questões, dilemas e alternativas

\section{Considerações acerca do tema "desenvolvimento": Reflexão crítica socio-histórica e geopolítica}

Considerations on the theme "development": Critical socio-historical and geopolitical reflection

Considérations à propos du thème "développement»: Réflexion critique socio-

historique et géopolitique

João Carlos Graça

(2) OpenEdition

Journals

Edição electrónica

URL: http://journals.openedition.org/configuracoes/8496

DOI: $10.4000 /$ configuracoes.8496

ISSN: $2182-7419$

Editora

Centro de Investigação em Ciências Sociais

Edição impressa

Paginação: $36-58$

ISSN: 1646-5075

Refêrencia eletrónica

João Carlos Graça, « Considerações acerca do tema "desenvolvimento": Reflexão crítica socio-

histórica e geopolítica », Configurações [Online], 25 | 2020, posto online no dia 21 junho 2020,

consultado o 23 junho 2020. URL : http://journals.openedition.org/configuracoes/8496 ; DOI : https:// doi.org/10.4000/configuracoes.8496 
Graça, João Carlos - Considerações acerca do tema "desenvolvimento": Reflexão crítica socio-histórica e geopolítica. Configurações, vol. 25, 2020, pp. 36-58.

\title{
Considerações acerca do tema "desenvolvimento": Reflexão crítica socio-histórica e geopolítica
}

JOÃO CARLOS GRAÇA*

SOCIUS/CSG, ISEG, Universidade de Lisboa

\begin{abstract}
Resumo
O tema "desenvolvimento" é objeto de análise, as principais discussões correlativas sendo colocadas em contexto socio-histórico. As dimensões económicas são articuladas com os aspetos políticos e culturais, ficando sublinhada a importância das diferenças de trajetória das várias sociedades. Em particular, chama-se a atenção para o ambiente internacional pós-1945 e as descolonizações, os quais verdadeiramente produziram o presente quadro global de discussão destes problemas, e para acontecimentos mais recentes, como o fim da Guerra Fria e a presente emergência da República Popular da China. É destacada a importância da superação duma atitude de eurocentrismo na consideração deste grupo de assuntos. Fica também expressa divergência quanto aos fundamentos e ao valor de algumas posições teóricas de ceticismo e pessimismo relativamente ao desenvolvimento.
\end{abstract}

Palavras-chave: Desenvolvimento, história das ideias, contexto socio-histórico, política internacional.

\footnotetext{
Abstract

Considerations on the theme "development": Critical socio-historical and geopolitical reflection

The theme "development" is the focus of analysis, with the main correlative discussions being placed in socio-historical context. Economic dimensions are articulated with political and cultural aspects, highlighting the importance of the differences in the trajectory of various societies. Attention is particularly drawn to the post-1945 international environment and the decolonisation processes, which have truly produced the current global framework

*Email: jgraca@iseg.ulisboa.pt
} 
for the discussion of these problems, and for more recent events such as the end of the Cold War and the current emergence of the People's Republic of China. The importance of overcoming an attitude of Eurocentrism in the consideration of this group of subjects is highlighted. Divergence is also expressed regarding the foundations and the value of some theoretical positions of scepticism and pessimism regarding development.

Keywords: Development, history of ideas, socio-historical context, international politics.

\begin{abstract}
Résumé
Considérations à propos du thème "développement » : réflexion critique socio-bistorique et géopolitique

Le thème «développement» fait l'objet d'analyse, les principales discussions corrélatives étant placées dans un contexte socio-historique. Les dimensions économiques sont articulées avec les aspects politiques et culturels, l'importance des différences dans la trajectoire des différentes sociétés étant soulignée. L'attention est en particulier attirée sur l'environnement international post-1945 et sur les décolonisations qui ont véritablement produit ce cadre mondial de la discussion de ces problèmes, et sur des événements plus récents tels que la fin de la Guerre Froide et la présente émergence de la République Populaire de Chine. L'importance de surmonter une attitude d'eurocentrisme lors de l'examen de ce groupe de sujets est soulignée. Une expression de divergence est également exprimée par rapport aux fondements et à la valeur de certaines positions théoriques de scepticisme et de pessimisme à l'égard du développement.
\end{abstract}

Mots-clés: Développement, histoire des idées, contexte socio-historique, politique internationale.

\title{
Introdução
}

É hoje em dia muito frequente a expressão da ideia de que o próprio conceito de "desenvolvimento" padeceria dum irremediável viés etnocêntrico. Está também na moda argumentar pelos seus alegadamente incontornáveis limites físicos e ecológicos. Tendo a discordar de tais ideias e tentarei explicar porquê, procurando tanto quanto possível contextualizar os debates.

\section{Origens e migrações}

É verdade que as noções estreitamente correlatas de progresso e de desenvolvimento são habitualmente consideradas reportando-as a um universo mental europeu. Trata-se antes de tudo, recordemo-lo, da famosa "querela dos antigos e dos modernos" em que se procurou, na França e no tempo do reinado de Luís XIV, indagar se os europeus da segunda metade do século XVII teriam ou não ultrapassado os povos da Antiguidade, particularmente os romanos e referindo-se 
acima de tudo a manifestações artísticas. As noções predominantemente cíclicas teriam, neste caso, dado lugar a uma conceção 'linear e progressiva' do tempo histórico. Não que o confronto com os modelos fornecidos pela Antiguidade fosse em si mesmo uma novidade, bem pelo contrário: todo o 'Renascimento' consiste precisamente nisso mesmo: um elogio feito aos< antigos (por comparação com a 'Idade das Trevas' intermédia), mas também uma emulação daqueles e um propósito declarado de os ultrapassar: "cale-se de Alexandre e de Trajano a fama", etc. Mas no caso da famosa querela o assunto teria ficado definitivamente encerrado: duma vez por todas, os europeus modernos tinham oficialmente ultrapassado os antigos em criatividade, discernimento, civilização material e domínio consciente do mundo (e, supostamente, também de si mesmos).

As ideias migram sem dúvida muito, mantendo algo dos seus traços definidores, mas também sofrendo mutações significativas. Da "querela dos antigos e dos modernos" podemos legitimamente passar para a Riqueza das Nações, de Adam Smith (1999), publicada pela primeira vez na Escócia em 1776 e na qual constitui um problema fulcral saber se os "progressos da opulência", aliás considerados inegáveis, podem ser mantidos indefinidamente; ou se, pelo contrário, eles deverão em todos os casos refluir a partir de determinado ponto, as economias e as sociedades tendo inevitavelmente trajetórias evolutivas pautadas por corsi $i$ ricorsi, isto é, por ciclos. Também é digno de registo o facto de Adam Smith atribuir os tais progressos da opulência à crescente divisão do trabalho e à cada vez maior utilização de máquinas nos processos produtivos - facto esse cuja origem considera, por sua vez, poder referir-se, dividindo equilibradamente os méritos, quer aos artesãos quer aos "filósofos", isto é, aos cientistas, que assim estariam já a promover a transformação parcial das técnicas empíricas em verdadeiras 'tecnologias'.

A tomada de partido pela ideia de um "progresso indefinido" é entretanto muito clara na obra de Marie-Jean Caritat, aliás Condorcet (1794-95), 'otimista da vontade' até ao fim, apesar das agruras das suas circunstâncias pessoais; e acima de tudo também 'otimista do pensamento', tendendo aliás para a noção de um progresso continuado e indefinido como se de um 'momento cartesiano' se tratasse com esta sua 'verdade autoevidente', ou com aquilo que nos apresenta como tal. A possibilidade de reversão dessa tendência progressista, alegadamente ínsita na história da espécie humana, existe porém, admite Condorcet, que a esse respeito cogita en passant sobre a eventualidade de colisão da Terra com um cometa. Caso, já se vê, para se retorquir que a um gaulês só mete mesmo medo a ideia de 'o céu Ihe cair em cima a cabeça'... o que, de resto, pode bem acontecer-lhe, como de vez em quando (e mais habitualmente a respeito de um qualquer Shoemaker-Levy ou afins) a astronomia vem hoje em dia recordar-nos.

Mais ainda, esse tal progresso indefinido, reportado por Condorcet antes de tudo às ciências, diria respeito a um décimo (e definitivo) estádio na evolução da espécie humana, pelo que a este cofundador do sistema decimal parece autoevidente também que se estaria a entrar numa época verdadeiramente nova, 
radicalmente nova, a ponto de a escala histórica decimal ficar totalmente cumprida, ou percorrida, ao se iniciar um período que deveríamos pois considerar em boa verdade já "pós-histórico". Ou então, simetricamente, postulando que até então teria decorrido apenas a pré-história da humanidade; e que a história verdadeira, plenamente humana porque plenamente consciente, talvez já sem verdadeiros obstáculos 'institucionais' (porque já proclamada a República Francesa), mas visando sobretudo os progressos das ciências e das tecnologias e os melhoramentos materiais na esfera económica, seria a que se trataria de percorrer dali em diante.

As ideias, já o escrevi, migram mesmo muito, mudando significativamente durante os referidos processos migratórios. Os economistas políticos da que já foi chamada "escola ricardo-malthusiana" cogitaram demoradamente, na viragem de século e nos começos do século XIX, acerca duma putativa cessação definitiva do crescimento económico, induzida por escassez de recursos naturais (sobretudo terras cultiváveis) e aumento excessivo das populações humanas. Veio mais tarde a designar-se essa eventualidade como "estado estacionário", e é inegável que pelo menos em parte esse grupo de indagações serviu como importantíssimo dispositivo retórico visando provar a ideia de inutilidade de quaisquer esforços redistributivos (para quê pensar em fornecer recursos adicionais aos pobres, se eles com isso aproveitam sobretudo para fazer mais filhos, aumentando assim a oferta de mão-de-obra e induzindo nova descida dos salários?), bem como a inevitabilidade da pobreza generalizada da maioria da população, mesmo nos países mais ricos (cf. Malthus, 1980; Graça, 2008).

Todavia, para Karl Marx, famosíssimo 'crítico da economia política' (ou, o que vem talvez a dar no mesmo, 'economista político crítico'), em meados do século XIX todas estas especulações e estes factos demandavam explicações alternativas, adentro dum quadro cognitivo radicalmente diverso. Os dispositivos mentais associados ao tema do crescimento indefinido voltam, entretanto, a expressar-se com clareza no seu discurso. O "capital", argumenta Marx (1969, 2012), dinheiro que circula para crescer interminavelmente, estaria a revolucionar por completo o mundo revolucionando antes de mais a vida económica através dum grupo de processos verdadeiramente merecedores do epíteto de "fáusticos". A célebre personagem de Goethe, recordemo-lo, teria pactuado com Mefistófeles a entrega a este da sua alma, mas apenas quando Fausto se desse por plenamente satisfeito 'neste mundo'. A salvação provisória de Fausto residiria então, acima de tudo o mais, na sua própria insatisfação. Analogamente, para o capital tratar-se-ia sobretudo desse movimento perpétuo, de crescer sem um fim à vista e sabendo aliás que ele não pode existir, ou que não é 'deste mundo'. Crescer indefinidamente, sem um limite assinalável, tendendo para infinito: eis pois a regra processual básica, incluída na lógica íntima do capital.

Havia, reconhecidamente, mais do que um 'lado escuro' em toda esta história. O "trabalho do negativo" comportava: a destruição violenta dos modos de 
produção pré-capitalistas, fosse por "acumulação primitiva do capital" (separação dos produtores e dos meios de produção com recurso a processos não-económicos, isto é, pelo exercício da violência direta), fosse em resultado da lógica operativa do capital triunfante no seu 'normal' funcionamento; a erradicação de inteiras civilizações não-europeias, militarmente submetidas, reduzidas à subalternidade ou mesmo materialmente obliteradas por completo; não apenas pobreza continuada, mas em boa verdade a pauperização da maior parte da sociedade; enfim, a proletarização da vasta maioria da população nos países de maior 'desenvolvimento' capitalista, os próprios seres humanos, ou as suas capacidades criativas, reduzidos assim à condição de mera mercadoria "força de trabalho". A esperança, aqui também feita certeza autoevidente, era que a "negação infinita" de que o proletariado era a vítima, sonegando-lhe de facto o reconhecimento da própria condição humana, acabasse por gerar a revolta desta classe universal, a cuja comum condição seria conduzido o conjunto dos explorados e oprimidos. Os alvos da tal 'negação infinita' não teriam ipso facto também nada a perder, e tão-pouco a esconder (dos outros ou de si próprios), pelo que poderiam/deveriam fundar uma organização social radicalmente nova. Se na economia capitalista as acrescidas contradições intrínsecas do capital desembocavam em baixa continuada da taxa de lucro, competição acrescida e crises cada vez mais frequentes e mais pronunciadas, a miséria emanando aqui diretamente (e contraditória ou paradoxalmente) da sobreprodução, na vindoura sociedade socialista a condição humana poderia ser simultaneamente redescoberta e reinventada, o pleno desabrochar, ou o crescimento (de novo) potencialmente ilimitado das 'forças produtivas' cumprindo assim as promessas do lluminismo e, em boa verdade, revelando os segredos mais profundamente contidos em toda a trajetória histórica anterior.

\section{Império, guerra e paz}

Os ciclos de acumulação capitalista continuaram bem depois da morte de Marx, e decerto muito para além daquilo que ele teria esperado. O crescimento económico prosseguiu, sendo ao longo do século XX submetido aliás a técnicas e processos de medida acerca dos quais o coautor do Manifesto do Partido Comunista, evidentemente, não podia sequer sonhar. Mais ainda: muito desse crescimento económico ocorreu em contextos que visaram ou domesticar as lógicas do capital, ou mesmo superá-las definitivamente.

Mas convém não nos apressarmos demasiado na narrativa histórica. No período imediatamente subsequente à morte de Marx o facto epocal definidor foi sem dúvida a expansão imperial, ocorrendo em regime de competição entre as diversas potências europeias (acrescidas dos EUA e do Japão), através da qual se procurou transferir tensões sociais nos países daquilo que veio mais tarde a ser designado como "centro", em troca duma expansão feita explicitamente à custa 
da "periferia", por via dos típicos pactos coloniais, violadores declarados das normais "regras de mercado" através de múltiplas regulamentações, mas garantindo benefícios excecionais e cruciais salvaguardas de defesa aos negócios (e também às populações) das metrópoles do "centro". Por este meio afiançava-se igualmente o atenuar e o desviar dos conflitos sociais, acompanhado da correlativa cooptação patriótica dos sindicatos e dos partidos socialistas emergentes em vários dos países mais "desenvolvidos" (Hobsbawm, 1989).

Como se sabe, este conjunto de processos desembocou, em Agosto de 1914, na I Guerra Mundial (Pauwels 2014), prolongando-se depois, em boa verdade, até 1945, naquilo que já foi designado como "segunda guerra dos trinta anos", isto é, todo o período 1914-45 (cf. Mayer, 1981; Canfora, 2006), na qual inúmeras componentes de conflitualidade social 'interna' e de antagonismos entre diferentes polities estiveram imbricadas de formas muito complexas e multímodas. $\mathrm{O}$ arranjo geopolítico subsequente, entretanto, produziu um grupo de configurações, às quais convém considerar com algum detalhe, garantindo no "centro" simultaneamente paz e prosperidade. Em particular, na Europa ocidental o crescimento económico continuado correspondente ao período dos chamados "trinta anos gloriosos" (1945-74) acomodou um conjunto de compromissos sociopolíticos que, de um lado, incorporavam o fait accompli do sufrágio universal (aliás agora verdadeiramente universal, porque também feminino), frequentemente acompanhado ainda pela existência de importantes tradições socialistas, fossem estas marxistas ou não. Nestes casos, o formato emergente foi o do chamado "estado do bem-estar", ou "estado social", com uma importante intervenção estatal nos processos económicos, visando assumidamente a satisfação dum grupo de necessidades consideradas básicas e inseparáveis duma verdadeira cidadania democrática: saúde, educação e segurança social, designadamente, foram objeto duma massiva 'desmercadorização' que correspondeu, no fundo, à consagração daquilo que já foi designado como terceira vaga de direitos de cidadania, a dos chamados "direitos sociais" (Marshall, 1950). Associado a isto havia usualmente também o propósito de garantir uma maior igualdade de oportunidades e uma maior mobilidade social vertical, quer intra quer inter-geracionalmente.

O assunto, porém, não se reduzia ao aplacar de possíveis conflitos sociais e à correlativa cooptação, agora 'supra-patriótica' (europeísta e/ou 'ocidentalista' ou 'atlantista'), dos sindicatos e dos partidos socialistas no âmbito dos países mais ricos e mais democráticos. Da parte dos gestores económicos de tais projetos estava presente também a assunção explícita da exequibilidade do propósito de garantir quer um crescimento continuado das economias, quer o atenuar significativo das respetivas tendências cíclicas. Noutros termos, tratou-se do triunfo de ideias económicas ditas 'keynesianas', mas agora acompanhadas dum consciente e vincado viés 'desenvolvimentista'.

Este facto traduzia, pelo menos em parte, a enorme vantagem fáctica gozada no imediato pós-1945 pelos EUA, que sozinhos ficaram momentaneamente (dada 
a ruína simultaneamente infligida por europeus e japoneses) com mais de 30 por cento do PIB mundial. Daqui resultou, de resto, o famoso "plano Marshall", através do qual se tratava antes de mais, para os EUA, de garantir procura continuada para um sistema económico interno em risco iminente de sobreprodução, e necessitando pois das exportações como substituto da enorme procura militar que, no caso norte-americano, tinha sido a verdadeira alavanca para a cabal superação da crise de 1929-33 - o 'New Deal' rooseveltiano sendo, quanto a isso, bem menos eficaz do que geralmente se assume (Pauwels, 2002). Nos EUA, dada a posição de vantagem geopolítica gozada, e dada também a fraqueza das tradições sindical e socialista 'nativas', os progressos do modelo do "estado social" foram entretanto bem menores e sempre mais tardios do que na Europa ocidental.

Na grande república norte-americana floresceu entretanto a escola sociológica parsoniana, a qual acabou por vir depois a tornar-se mais ou menos hegemónica na maior parte dos países ocidentais, assente na prevalência de ideias de consenso e estabilidade e referindo-se a um modelo de regulação valorativa que expressava, na verdade, sobretudo o enorme acordo interno de que as elites (políticas, industriais e militares) norte-americanas beneficiaram no período imediatamente posterior a 1945, acordo sedimentado na prosperidade e no crescimento económico continuado, obviamente, mas também no culto coletivo das noções de excecionalidade e de papel exemplar de que alegadamente a nação-líder estaria investida, quando comparada com o "resto do mundo". Esta excecionalidade norte-americana esteve, aliás, nas origens da trajetória parsoniana, em marcada proximidade com uma autoimagem abertamente WASP (branca, anglo-saxónica e protestante) dos EUA: não por acaso, Talcott Parsons contribui decisivamente para a recuperação das teses weberianas sobre a ética protestante e o seu alegado propiciar do 'espírito do capitalismo', teses segundo o próprio Max Weber com uma validade muito limitada e, de resto, tendencialmente ultrapassadas já na primeira década do século XX.

A autoimagem coletiva duradouramente pilgrim dos EUA constituiu evidentemente um terreno muitíssimo fértil para esta recuperação serôdia dos temas associados à pretensa 'singularidade' protestante; mas Parsons veio depois a alargar, procurando simultaneamente secularizá-lo e universalizá-lo para além do estrito ambiente do protestantismo, o quadro cultural correspondente às sociedades "desenvolvidas": um empreendimento que, como se sabe, desembocou na assunção pelo seu discípulo Bert Hoselitz (1962) das célebres "variáveis de configuração" correspondentes a desempenho, universalismo, especificidade e neutralidade afetiva (por oposição a adstrição, particularismo, difusidade e afetividade) enquanto quadro valorativo supostamente indutor do desenvolvimento. 


\section{Heterodoxias e ortodoxias}

Na Europa, por várias razões, a trajetória foi consideravelmente diversa. Desde logo, a guerra de 1914-18 produzira, como importante resultado imprevisto, a revolução soviética, a qual foi aliás um fator importante de apressamento do final do conflito bélico. O projeto soviético, embora oficialmente fundado nas ideias de Karl Marx, veio na verdade a apelar não tanto aos "proletários de todos os países", mas sobretudo às "nações e povos oprimidos" de todo o mundo. Dito de outro modo, se o 'contágio' soviético para oeste, embora inegável de início (revoluções alemã e húngara, "biénio vermelho" italiano...), foi rapidamente contido através dum "cordão sanitário" comportando um mix bem doseado de cooptação e violência, já entretanto a constituição da URSS, o seu inegável sucesso económico no período até 1941 (apesar de todos os bloqueios, de todas as agressões militares sofridas e de toda a guerra civil explícita ou larvar experimentada), a dimensão das suas realizações no plano 'social' (alfabetização universal, emancipação feminina, urbanização e industrialização aceleradas, rápida melhoria generalizada dos indicadores demográficos) e sobretudo o seu declarado apoio aos movimentos anticoloniais, em particular na Ásia, constituíram um fator duradouro de perturbação, que a paz posterior a 1945, com a correspondente hegemonia norte-americana, teve o encargo demorado e complexo de processar, filtrar, cooptar e, enfim, superar consistentemente.

Sob o ímpeto do exemplo/desafio soviético, os próprios EUA acolheram parcialmente o propósito da descolonização, ideia cujo âmbito de aplicação ficara no período de Woodrow Wilson limitada à Europa e sendo estritamente aplicada à custa dos vencidos de 1918. Já depois de 1945, com a fundação da ONU, o ressurgimento da China no palco da Weltpolitik e as independências da Índia britânica, das Filipinas e da Indonésia, o caminho ficou aberto para uma vaga geral de descolonizações que da Ásia de sudeste alastrou depois ao Médio Oriente e ao conjunto da África, tendo enfim vindo a suscitar também na América Latina propósitos generalizados de "segunda independência". É neste contexto global que, em linhas gerais, são formulados os problemas de "desenvolvimento" tal como hoje ainda somos usualmente capazes de os pensar. É no âmbito de instituições movendo-se na orla da ONU, mas onde a hegemonia norte-americana é mais clara (FMI, Banco Mundial, OCDE), que os temas da convergência ou divergência económicas (catching up ou lagging behind) são enunciados, os EUA produzindo abundantes 'narrativas' socioeconómicas e políticas, em geral postulando a desejável e previsível convergência dos países mais pobres com os mais ricos, caso os modelos de organização social norte-americanos fossem copiados, as economias deixadas predominantemente entregues à regulação pelo mercado e as entradas de capital estrangeiro facilitadas, a subsequente integração destes países no mercado mundial conduzindo de forma esperável à sua convergência com os mais ricos. 
Entretanto, porém, a influência soviética, e depois igualmente a chinesa, constituíram importantes contrapontos a este modo operativo, porque vários casos de forte intervenção estatal foram promovidos, não raro com inegável sucesso, as próprias economias da Europa de Leste continuando aliás em trajetória de convergência económica com as mais ricas do Ocidente até meados da década de 1970. No resto do mundo a regra prevalecente foi porventura a da própria turbulência política, os EUA bastantes vezes aceitando ou promovendo compromissos políticos que incluíam estados 'desenvolvimentistas' economicamente muito interventivos (Coreia do Sul, por exemplo) ou, em variedade próxima, uma muito significativa componente de 'keynesianismo militar' (como, designadamente, no Paquistão), em todo o caso afastando tais sociedades de possíveis tentações de alinhamentos geopolíticos com 'o inimigo', mesmo que para isso fosse necessário (e frequentemente foi) mantê-las afastadas, e de forma muito marcada, da ortodoxia económica dita "neoliberal", a qual só veio a ser afincadamente promovida a partir de finais dos anos 1970, isto é, à medida que o modelo soviético se esgotava e se tornava menos e menos atrativo: com algumas raras exceções (como, em particular, o Chile de Pinochet) o lema neoliberal de "liberalizar, privatizar, desregulamentar" foi uma tríade só a partir de então consistentemente avançada como alternativa em matéria de políticas económicas, os falhanços da maior parte dos países do chamado "terceiro mundo" em obter o prometido catching up passando sistematicamente a ser atribuídos à ausência duma atitude coerentemente neoliberal, ou seja, a estados que alegadamente seriam de forma sistemática demasiado intrusivos.

Numa gíria algo mais sofisticada, isto passou pela defesa dum rule of law pensado à la Hayek, opondo-se a todas e quaisquer tendências dos poderes políticos para decisões discricionárias, isto é, propriamente políticas. Os poderes soberanos deveriam pois, como seria de esperar desta recuperação tardia dum filão importante de ideias da tradição liberal, fazer 'tão pouco quanto possível', 'o mínimo possível'. Este quadro orientador foi aplicado um pouco por todo o lado, no primeiro e mais ainda no terceiro mundo, isto é, nos países ricos alinhados com os EUA e também, de forma acrescida, nos países pobres do também chamado "Sul global", muitos deles ex-colónias que, apesar da descolonização, continuavam (e continuaram, e frequentemente ainda continuam) a não 'convergir', ou mesmo a 'divergir' dos países ricos.' Em nenhum caso, porém, tais receitas foram aplicadas

1 Quanto a este assunto, uma referência à parte deve ser feita a alguns casos de integração económica regional, designadamente os da UE e sobretudo da UEM. A adoção nestas de princípios de observância de regras comuns, obrigando à obediência a um grupo de ditames concebidos enquanto verdadeiro rule of law europeu, retira pouco a pouco aos governos dos diversos estados-membros a capacidade para quaisquer decisões de caráter eminentemente 'político', reduzindo-os assim ao desempenho, quais autarquias, de tarefas predominantemente 'administrativas', pensadas enquanto mera aplicação da referida 'lei europeia'. Trata-se aqui daquilo que Wolfgang Streeck (2016, p. 74-9, 154-9) considera ser o 'arranjo Hayekiano' sobre o qual a UEM estaria assumidamente fundada, o qual coloca obstáculos significativos à tomada de decisões quer ao nível dos estados-membros quer no próprio centro. Segundo Streeck "... quanto mais diverso for um regime multinacional em termos das estruturas e interesses nacionais, menos provável é que o que seu 
de forma tão irrestrita, ao mesmo tempo selvática e obstinadamente, como no processo da enorme transformação dos países da antiga esfera soviética em 'novo terceiro mundo', na sequência da catastrófica "transição para o mercado" ocorrida no período posterior a 1990.

Sublinhe-se que, se aquando do Plano Marshall os países da Europa ocidental foram economicamente ajudados tendo em vista a promoção das exportações norte-americanas, a verdade é que o aspeto imediatamente geopolítico do problema, isto é, a proximidade, o poder e a influência da URSS no período pós-1945, nunca foi deixado de lado. Tratou-se, durante todo o tempo, de aceitar os compromissos que se revelassem politicamente necessários (incluindo, tal como já referido, "estados sociais" muito desenvoltos), visando evitar a todo o custo a ameaça (ou a possível tentação) comunista-soviética. No terceiro mundo, entretanto, níveis bastante elevados (mesmo anomalamente elevados, pelos padrões anglo-saxónicos) de intervenção estatal foram também tolerados, ou mesmo promovidos. 0 próprio panorama intelectual dos países ocidentais traduziu o reconhecimento de vários destes aspetos associados ao desenvolvimento de países mais pobres, que todavia acabam por arrancar para processos de crescimento económico bem-sucedido, ou seja, os chamados latecomers. A obra de Alexander Gerschenkron (1962) é decerto exemplar quanto a isto: trata-se de admitir, ou mesmo de postular, que os processos de arranque e de convergência mais tardios não copiam a trajetória dos que primeiro arrancaram, bem pelo contrário, um certo número de aparentes 'anomalias' são aí perfeitamente identificáveis como padrão, entre elas precisamente a maior importância da intervenção estatal direta na economia, as maiores vantagens duma escala acrescida e, enfim, o superior significado genérico dos aspetos culturais: ou, noutros termos, daquilo que Gerschenkron designou como "combustíveis ideológicos" capazes de mobilizar eficazmente, através de vários entusiasmos coletivos, as energias até então desperdiçadas de várias sociedades, por uma razão ou outra bloqueadas no seu arranque para processos de desenvolvimento económico.

\section{Desenvolvimento bloqueado, centro e periferia}

Em paralelo, dúvidas crescentes foram suscitadas quanto à própria noção genérica de que os países mais pobres seriam verdadeiramente mais "atrasados" ou menos "desenvolvidos", tratando-se pois, para eles, de imitar eficazmente o modelo representado pelos mais ricos percorrendo as suas sucessivas fases, como

corpo governante seja capaz de tomar medidas discricionárias para corrigir os resultados dos mercados. Que essa federação de estados pode mais facilmente decidir em libertar as economias da intervenção estatal - i.e., quanto àquilo a que a sociologia política contemporânea chamou 'integração negativa' - foi algo apontado por Friedrich von Hayek já em 1939. [...] a integração económica entre estados simultaneamente diferentes e iguais pode proceder somente sob a forma de integração dos mercados: a institucionalização dum mercado único livre de intervenção estatal, porque os estados-membros não serão capazes de concordar no que quer que seja senão nisso" (Streeck, 2016, p. 159; itálicos no original). 
sugerido emblematicamente por Walt Whitman Rostow (1960). Em alternativa a este dispositivo intelectivo, uma influência aumentada foi pouco a pouco adquirida por diversos grupos de teorizações, sublinhando: os vários impedimentos possíveis dos processos de desenvolvimento socioeconómico, desembocando em casos de verdadeiro "desenvolvimento bloqueado" (arrested development); o caráter frequentemente cumulativo destes bloqueios; os traços de "causalidade circular cumulativa" correspondentes quer aos casos de sucesso quer aos de insucesso; enfim, o facto crucial de o sucesso de uns e o insucesso de outros estarem (ou poderem estar) relacionados, as ligações não sendo usualmente de vantagens mútuas, mas tendo em vez disso uma índole predatória.

"Centro" e "periferia" foram os termos cruciais usados para designar esta relação, ou o que se supunha ser um traço fundamental da coexistência de países ricos e países pobres, ou pelo menos de alguns deles. As relações formalmente coloniais de outrora teriam desaparecido, é verdade; mas estariam a ser substituídas por configurações socioeconómicas fácticas consideradas "neocoloniais", a periferia sendo sobretudo produtora e exportadora de materiais pouco elaborados; e sofrendo de bloqueios diversos induzidos: pela existência dum sector tradicional muito amplo, o qual tenderia a sapar (economicamente, mas também cultural e demograficamente) as possibilidades de arranque sustentado dos débeis sectores modernizados, mas também pela própria intensidade da ligação aos países do "centro", ou pelo tipo de ligação prevalecente, o qual tendia ao perpetuar da situação de assimetria, não à sua superação.

Para além de induzir e legitimar diversos empreendimentos de desenvolvimento assentes na ideia de um 'desligar' seletivo do comércio internacional (e até mesmo num propósito consciente de autarcia parcial), mais do que na de fomento do referido comércio, para a promoção do projeto desenvolvimentista, este quadro mental apontou também para intuitos de intervenção estatal significativa. Não é, pois, de estranhar que várias ideias económicas e sociais anteriores, não raro evocativas do legado teórico de Friedrich List, tenham vindo assim a fundir-se aqui com o mais recente influxo keynesiano (tal como ficou bem patente na generalidade da corrente dos chamados economistas 'cepalinos': James Arthur Lewis, Raúl Prebisch, Celso Furtado e outros, cf. Fonseca 2000) e, enfim, com diversas versões de marxismo e neomarxismo, produzindo o panorama intelectual genericamente associável a um grupo de autores do qual podemos porventura indicar, como representantes mais notáveis, André Gunder Frank, Samir Amin, Immanuel Wallerstein e Giovanni Arrighi (1999, 2009).

O grupo de questões associadas ao problema do "desenvolvimento bloqueado" encontrou também um eco na politologia norte-americana, mas sofrendo aqui significativas reformulações. Em concreto, Samuel Huntington (1968), numa obra precisamente acerca dos problemas correspondentes à "ordem política em sociedades em mudança", considera as dificuldades correspondentes a possíveis 
processos de "modernização" que todavia tendem a ser conflituais com o próprio projeto de desenvolvimento. Huntington organiza o seu raciocínio em torno da noção de ciclos políticos, o decurso dos quais alegadamente envolve diversos níveis de "participação" e de "institucionalização". Vários entraves poderiam criar uma tensão difícil de ultrapassar entre a lógica associada à modernização e a do desenvolvimento: para assegurar a primeira, argumenta, enfraquece-se por vezes o desenvolvimento político, assim fazendo entrar em cena os interesses e a corrupção. A conclusão é de que só através dum crescimento lento, bem estruturado em torno de situações institucionais favoráveis, se conseguiria a prossecução eficaz dos objetivos de desenvolvimento. Na verdade, e ainda segundo Huntington, as tendências modernizadoras possibilitariam dois tipos de sistemas políticos: um deles correspondendo ao predomínio da chamada "sociedade civil", o outro ligado àquilo que designa como "sociedade pretoriana". Nas sociedades ditas "pretorianas' predomina um ambiente de anomia no sentido durkheimiano do termo: os grupos de oposição tendem a recusar a negociação, o que conduz a um generalizado subdesenvolvimento institucional, em tais circunstâncias cada interveniente utilizando de forma mais ou menos desregrada os meios ao seu alcance: no caso dos operários, as greves; com os ricos, a corrupção; para os militares, o golpe de estado; e assim sucessivamente. Quer o clero, quer os sindicatos, quer as universidades operam aqui habitualmente de forma partidarizada, os próprios níveis de participação acrescidos tendendo, neste contexto, a fazer acelerar o declínio geral.

$\mathrm{O}$ argumento de Huntington corresponde assim a um esquema de propiciações diversas, os seus raciocínios sugerindo a ideia dum ciclo, ou daquilo que pode desembocar num ciclo: maiores níveis de institucionalização tendem a 'civilizar', argumenta; facto que, pelo seu lado, tende a induzir uma maior participação; o que, nalguns casos, pode tender a 'pretorianizar'; facto esse que, em princípio, deverá finalmente conduzir a uma menor participação (e assim ao recomeço do processo). Segundo raciocina, observa-se genericamente um nível de participação fraco nas chamadas 'sociedades civis orgânicas', sendo que esse nível passa a médio, segundo o mesmo critério, para as 'sociedades civis liberais', atingindo-se com as 'sociedades civis participativas' um nível elevado. Daí pode frequentemente passar-se, por redução dos valores em matéria de institucionalização, para as chamadas 'oligarquias pretorianas de massa', onde a participação continua a ser forte, evoluindo-se depois destas para as 'oligarquias pretorianas radicais', com níveis médios de participação e chegando-se enfim ao tipo das oligarquias pretorianas propriamente ditas, nas quais o nível de participação é fraco. A argumentação de Huntington veicula uma óbvia desconfiança, aliás de inclinação tipicamente 'liberal', relativamente à própria participação política, de cujo crescimento irrestrito se receiam as possíveis derivas 'pretorianas'. Em parte por isso mesmo, tem suscitado várias críticas, entre outras a de se tratar dum modelo marcadamente etnocêntrico, extrapolando abusivamente com base na experiência política norte-americana. Noutros termos, as sociedades da América Latina configurariam um 
caso de desenvolvimento arrestado, sim, os bloqueios fazendo a trajetória histórica desembocar não num progresso continuado, antes em sucessivos corsi $e$ ricorsi. Mas isso seria uma verdade sobretudo em termos políticos, mais do que económicos. E o principal bloqueio ao desenvolvimento não seria de origem externa (comércio internacional ou outro), residindo antes nas próprias sociedades "bloqueadas", onde razões de ordem diversa, culturais e outras, fariam propender para a excessiva participação e a deficiente institucionalização, por isso induzindo uma propensão sistemática para a anomia, o quadro 'pretoriano' e o ciclo vicioso.

\section{Eurocentrismo e depois}

Mais do que as implicações e ramificações expressas em projetos de política económica, porém, ou do que a réplica polémica suscitada numa obra como a de Huntington, os autores que avançaram os temas das relações centro-periferia devem ser considerados importantes sobretudo pelo que representaram quanto ao intuito duma visão menos eurocêntrica, ou mais 'descentrada' do panorama euro-norte-americano, ao qual as lucubrações relativas a "desenvolvimento" usualmente se reportam de forma primordial. Acolhendo igualmente o contributo de historiadores da longue durée social (económica, cultural, política), tais como Fernand Braudel (1979)², Paul Bairoch (1999) e Angus Maddison (2007), para além dos insights inspiradores de Joseph Needham, Martin Bernal, Eric Williams, CLR James, Eric Williams, James Blaut (2000) e Jack Goody, entre tantos outros, este feixe de debates encontra sem dúvida um culminar provisório na obra de Kenneth Pomeranz (2000) e nas suas teses relativas à chamada "grande divergência". Até cerca de 1800, argumenta Pomeranz, o PIB por habitante europeu não se teria demarcado significativamente dos níveis atingidos na China, que de resto teria excedido consistentemente as marcas da Europa durante vários séculos. A singularidade (e a excecionalidade 'positiva') da trajetória europeia teria assim ficado desenhada muito depois dos Descobrimentos, para já não falar do Renascimento; e deveria muito pouco a qualquer pretensa inclinação ("greco-romana", "judaico-cristã", protestante ou outra) para a racionalidade, a ciência ou a tecnologia. Na verdade, ter-se-ia tratado acima de tudo de saber superar a chamada "armadilha malthusiana" usualmente colocada a sociedades com trajetórias semelhantes, antes de mais através do recurso a fontes de energia alternativas à madeira (designadamente, o carvão), o que no caso europeu teria evitado as desflorestações massivas típicas de situações análogas, bem como as correspondentes catástrofes ecológicas. E esse processo teria, por sua vez, sido suportado pela integração da economia

2 A obra de Fernand Braudel e de resto, notemo-lo, também a de Vitorino Magalhães Godinho, foram objeto de um repetido reconhecimento nos escritos Immanuel Wallerstein quando este apresenta os contributos dos historiadores da longue durée para a teorias do 'centro-periferia' e do chamado 'sistema mundial moderno'. 
das plantações americanas nos circuitos económicos liderados pelos europeus: o Caribe, essa 'América africana' artificialmente produzida pela tremenda engenharia social da expansão europeia, teria mesmo constituído o protótipo de todas as outras "periferias" posteriores, importando massivamente bens de produção (os próprios escravos e os bens manufaturados necessários à sobrevivência destes, os quais provinham primeiro da Índia, mais tarde da Grã-Bretanha) e exportando produtos agrícolas simples e 'trabalho-intensivos'. As brutais realidades da ocupação das terras de todo uma continente novo, as Américas, tratadas como 'terra virgem' através do extermínio dos respetivos nativos, acompanhada da escravização em massa e tráfico dos africanos (tráfico que, sublinhe-se, cresceu vertiginosamente ao longo de setecentos, atingindo valores máximos no final desse século) são assim identificadas como a 'infraestrutura', a 'cave funda e oculta' que verdadeiramente sustentaria e explicaria o mui decantado "milagre europeu".

Análogo esforço de descentramento geográfico tem perpassado igualmente a obra de muitos outros autores, de entre quais vale a pena mencionar John $\mathrm{M}$. Hobson, Sugata Bose, Alexander Anievas e Karem Nisancioglu, Jared Diamond, Ian Morris e Phillip Hoffman. Hobson (2004) faz das dívidas (cultural, científica, económica, etc.) da Europa para com a Ásia o tema central da sua obra. Bose (2004, 2006) explora o tema da estreita dependência do sucesso britânico dos factos fundamentais que foram o seu domínio militar e a exploração económica da Índia. Anievas e Nisancioglu (2015) tomam a Europa como "periferia" asiática até muito tarde, fosse política, militar, económica ou culturalmente, uma cadeia de eventos ocorrendo entretanto, permitindo aos europeus aproveitar as vantagens associadas aos "privilégios do atraso"; e isto num mundo pautado por ritmos diversos e intercruzados de "desenvolvimento desigual e combinado". Diamond $(1999,2007)$ trouxe para o primeiro plano da investigação a consideração de fatores diversos, geográficos, epidemiológicos e militares, frequentemente deixados de lado nas indagações socio-históricas, bem como a possibilidade muito real de refluxos civilizacionais massivos, correspondentes a casos de 'colapso' de sociedades inteiras. Morris (2011) embarcou num projeto visando a comparação da Europa e da China no longuíssimo prazo, concluindo pelo fim iminente do domínio europeu, mas também pela necessidade de produção duma realidade 'pós-humana' (apelando, em particular, à noção de androides, ou híbridos homem-máquina) como condição de sobrevivência da própria espécie, trate-se da questão dos riscos de conflitos bélicos e de falências políticas integrais (state failures), trate-se acima de tudo dos alegadamente insustentáveis níveis de consumo de recursos, particularmente energia. Indicador bem seguro da existência de conflitos académicos insanáveis, valorativos ou outros, é decerto curioso e digno de nota que o título da obra de Morris, Why the West rules (For now)?, tenha um eco tão direto e tão óbvio no do livro de Anievas e Nisancioglu (2015), How the West came to rule, sem que todavia Morris seja aqui referido, sequer uma única vez. Phillip Hoffman (2015), pelo 
seu lado, pergunta-se 'porque é que a Europa conquistou o mundo', fornecendo uma resposta em chave militar, na qual a ideia de "torneio" incentivando várias potências rivais a permanentes melhoramentos técnicos é crucial, mas uma certa dose de isolamento pode por vezes ser conveniente (daí o ascendente adquirido em certas ocasiões não por europeus centrais, mas pela Rússia, por exemplo); e a variedade de inimigos que se tem de defrontar pode induzir path-dependencies tecnológicas lesivas: como teria acontecido designadamente com a China tradicional, dado o tipo de inimigos que habitualmente combatia, os cavaleiros-arqueiros das estepes da Ásia central, o que teria desincentivado o uso da pólvora.

É importante considerar o ambiente global adentro do qual tendem a emergir estas visões menos eurocêntricas. Não obstante tudo o que ficara intentado em matéria de projetos 'desenvolvimentistas' (marxistas, 'cepalinos', keynesianos ou outros), foram todavia as experiências de catching up de países não-europeus obtido inicialmente através duma orientação predominante para as exportações, em particular a experiência coletiva dos "tigres asiáticos", que criaram o ambiente geral que veio a permitir abalar mais significativamente (e talvez definitivamente) a tendência para pensar a categoria "desenvolvimento" enquanto assunto europeu ou euro-norte-americano por excelência, o resto do mundo limitando-se quanto a esse assunto a 'seguir o líder'. Os "tigres asiáticos", sublinhemo-lo, escoltaram já na verdade a experiência anterior do Japão, mas a integração deste último no sistema dos países da 'primeira liga' à escala global é um facto já da viragem de século XIX/XX, particularmente através da guerra russo-japonesa de 1904-05 (primeiro e então excecionalíssimo caso de não-europeus impondo uma derrota militar a europeus) e da constituição do império japonês na Ásia do sudeste. Os japoneses foram, de resto, pensados depois disso predominantemente como "europeus honorários" (ou na verdade como "brancos honorários", para recorrer a uma categoria oficialmente consagrada na África do Sul do apartheid), ao passo que profundas dúvidas se foram levantando no Ocidente também quanto à índole verdadeiramente europeia da Rússia (numa linha argumentativa que, como se sabe, viria a desembocar na oficial defesa da "civilização europeia" pelos nazis na frente leste, durante a II Guerra Mundial, em oposição/confronto "existencial" com as chamadas "hordas asiáticas").

Se o surgimento dos "tigres" depois do Japão foi já um facto muito significativo, assinalando o começo do destronar do centro 'atlântico' (ou euro-norte-americano) da economia global, muito mais importante ainda foi sem dúvida a emergência, depois daqueles, da República Popular da China, acompanhada do lento deslocar para sudeste do centro da iniciativa económica adentro da massa eurasiática. A RPC tem procurado, até ao momento com considerável sucesso, apoiar-se quanto ao seu discurso oficial quer na recuperação da história multissecular chinesa, quer na sua coloração político-ideológica, a plena transformação do antigo império em nação multiétnica moderna tendo sido alegadamente 
concluída com a República Popular, que teria outrossim permitido a ultrapassagem do "século das humilhações": desde 1839, aquando da abertura, imposta pelo Reino Unido, ao livre-câmbio internacional, em particular o livre-câmbio do ópio, até ao triunfo do Partido Comunista na guerra civil, em 1949. O recente surto económico da China, porém, ocorreu de facto no contexto duma enorme abertura quer ao mercado, quer ao puro e simples capitalismo. Acompanhada dum aumento muito significativo das desigualdades, a riqueza cresceu entretanto vertiginosamente, seja medida sob a forma do PIB por habitante (simples ou em "paridade de poder de compra") ou com base noutro qualquer indicador. A massa de pessoas (várias centenas de milhões) reconhecidamente tiradas da pobreza constitui um feito absolutamente inaudito em toda a trajetória da humanidade, que só não é celebrado habitualmente nos manuais de história universal porque estes, até aos nossos dias, para além do viés eurocêntrico, continuam a ocupar-se mais de guerras, colapsos e desastres do que façanhas de beneficência e filantropia. O crescimento global da China foi, aliás, nas últimas décadas o único fator significativo de atenuação do crescimento das desigualdades ao nível global - e isso apesar do reconhecidamente excessivo aumento das suas assimetrias internas, sobretudo as inter-regionais.

Quer a tradição cultural anterior, onde a influência social dominante era a dos letrados (confucionismo) e onde a mobilidade social ascendente e descendente era muito superior à europeia, quer o legado político-ideológico mais recente (marxismo-leninismo, maoísmo) continuam entretanto a condicionar de forma muito significativa a evolução chinesa, na qual as empresas públicas permaneceram o vetor económico dominante e o setor bancário está sujeito a uma monitorização muito mais apertada do que no Ocidente (a China nunca abandonou o controle dos movimentos de capitais, por exemplo). Em paralelo, nos tempos mais recentes o caráter até há pouco export driven do crescimento económico também foi significativamente atenuado, passando a ser muito mais apoiado pela procura da próspera, já enorme e rapidamente crescente classe média 'doméstica', para além do próprio estado, cujos gastos têm sido aliás o principal esteio em períodos de relativo abrandamento (como o atual), resultante sobretudo do degradar da situação à escala global.

\section{Desequilíbrios e incertezas}

No momento em que este texto é escrito as tendências de longo prazo a nível mundial apresentam-se pouco claras, sendo muito elevada a dose de conflitualidade social, quer no interior dos vários países quer nas relações internacionais. Pelo menos uma parte dessas tendências desorganizadoras parece ficar a dever-se à perceção de ameaça que, do ponto de vista norte-americano, representam quer a emergência continuada (e cada vez mais autossustentada) da China, quer a recuperação da Rússia, que no período pós-leltsin tem mostrado uma desenvoltura e uma independência face ao colosso norte-americano que este decididamente não vê com bons olhos. Estes dois países, entretanto, face à hostilização comumente 
imposta pelos EUA, entraram assumidamente em trajetória de "parceria estratégica" continuada, ou declarado "destino comum", para além de envidarem múltiplos esforços de agregação de outros estados a que também os EUA transformaram em párias globais (Irão, Coreia do Norte...) e de conquista de simpatias e de mercados por parte de regiões ainda hoje consideradas "subdesenvolvidas", como acontece com a Ásia do centro e do sul, com a África e com a América Latina. Dito de outro modo, todas ou quase todas as regiões abrangidas pela descolonização pós-1945 estão de novo radicalmente up for grabs, os EUA (apoiados pelos seus subalternos: UE, Japão, Canadá, etc.) disputando de novo mercados e recursos à escala global com aquilo que para muitos efeitos práticos é percebido como um "bloco sino-soviético" redivivo e numa versão ampliada (e antes de mais económica) da primeira Guerra Fria, bloco agora liderado pela China via empreendimentos como a chamada Belt and Road Initiative, entre outros.

Este renovar da aliança China-Rússia é inegavelmente importantíssimo, sendo quanto a isso de recordar e sublinhar que a RPC ficou até à década de 1970 excluída da própria ONU (e do Conselho de Segurança desta) em virtude do veto norte-americano, consequência por sua vez da ficção até então prevalecente de que haveria 'duas Chinas', os norte-americanos tendo aquando da guerra civil apoiado a perdedora, mas acolhida à sua asa protetora em Taiwan, e que por isso deveria continuar a ser considerada a China 'legítima'. Sob a direção de Nixon e Kissinger os EUA reviram todavia drasticamente (e realisticamente) este alinhamento, procurando do mesmo passo acentuar o fosso China-URSS e enfraquecer esta última. Esta nova atitude prolongou-se depois para um tratamento comparativamente benevolente da China por parte dos EUA, decerto na expectativa de manter o país asiático sob controlo e culminando na sua integração também na Organização Mundial do Comércio. Este mesmo desenho mental levou inclusive, em determinada altura, a conjeturas várias (cf. Ferguson 2008) sobre a viabilidade duma simbiótica Chimerica (China + América) que na verdade se revelaram bastante fantasiosas ou meramente quiméricas, os EUA revendo mais recentemente a sua abordagem, e agora num sentido inequivocamente muito agressivo. Entretanto, se a reemergência da China, nos anos setenta, esteve largamente baseada na "diplomacia triangular" de Henry Kissinger, nova relação 'triangular' parece agora projetada pelos EUA e visando a União Indiana, com o propósito confesso de fazer acentuar a clivagem deste último país com o seu vizinho setentrional (e a história dos conflitos Índia-China é realmente muito longa), aproximando-o do mesmo passo dos norte-americanos, concedendo-lhe vantagens na importação de produtos em que ele eventualmente possa substituir a China e permitindo-lhe assim a ocupação dum 'nicho' de parceiro subalterno global dos EUA, designadamente em matéria de assuntos militares.

Equivale tudo isto a reconhecer que o futuro global é, e continuará decerto a ser, largamente uma caixa de surpresas. Se, por exemplo, as manobras norte-americanas de 'triangulação' diplomática ajudaram em tempos a República Popular 
da China, enquanto hoje parecem (contra aquela) sorrir à União Indiana, tudo isso tendeu e tenderá decerto a ter repercussões significativas em matéria de desenvolvimento, qualquer que seja o ângulo considerado. Todavia, penso que, algo paradoxalmente, aquelas tenderão a ser repercussões de sentido contrário ao visado por George Frost Kennan quando, em 1948, o diplomata norte-americano admitia abertamente que "temos 50 por cento da riqueza do mundo, mas apenas 6.3 por cento da sua população. Nesta situação, é inevitável que nos tornemos objeto de inveja e de ressentimento. A nossa tarefa no próximo período é inventar um padrão de relacionamentos que nos permita manter esta posição de disparidade. Não precisamos de nos enganar a nós próprios quanto a podermos, hoje em dia, suportar os luxos do altruísmo e da benfeitoria mundiais - objetivos irrealistas, tais como os direitos humanos, a subida do nível de vida e a democratização" (cit. in Loewen, 2007, p. 221). Chame-se-Ihe, "mão invisível", "astúcia da razão", "heterogonia de objetivos" ou o que mais se quiser: o facto é que, considerada na sua globalidade e ao longo de quase três quartos de séculos, o "espírito do mundo" (ou o que disso seja equivalente) me parece proceder de tal forma que, com a devida vénia à sua honestidade intelectual e sinceridade, em boa medida precisamente graças a Frost Kennan e consortes, as coisas na história universal, bem longe de ficarem congeladas, se movem predominantemente contra Frost Kennan e consortes...

\section{0 bebé e a água do banho}

Escrevi no início deste texto que discordava dos argumentos relativos aos limites físicos e ecológicos supostamente inultrapassáveis pelo crescimento e/ou o desenvolvimento. Em particular, as famosas teses de Nicholas Georgescu-Roegen (1995, 1999) quanto à prevalência incontornável dum princípio de entropia e à sua incompatibilidade com a ideia dum crescimento económico indefinido parecem-me resultar dum abuso metafórico na consideração dos factos sociais (incluindo os económicos), que só mesmo por analogias muito limitadas e controladas podem/ devem ser pensados recorrendo a modelos importados da física. Tudo o que sobe tem de descer? Talvez, mas a história humana consiste precisamente num esforço para evitar que assim seja. E essa tal parte do todo que, embora subindo, talvez não tenha necessariamente de descer, somos precisamente nós, os humanos, e a nossa história coletiva; história que, repito, pode ou não ser feita de progresso/desenvolvimento, tudo dependendo do que façamos com ela. Ora, quanto a tudo isso, a física ajuda-nos muito pouco. A ação humana engloba componentes de reflexividade, de performatividade (de "profecias autorrealizadas", como se diz, entre elas a do próprio "desenvolvimento") e outras ainda, atinentes à densidade e à complexidade da noosfera, acerca das quais a ciência física, e mesmo a biologia, nada nos dizem e nada nos podem dizer. 
Aquando da crise petrolífera do início dos anos setenta tornaram-se famosas as proclamações relativas à suposta necessidade dum "crescimento-zero" das economias, feitas pelo chamado "Clube de Roma" com base, entre outros, em argumentos formalmente 'ecológicos'. Foi este mesmo ambiente de início da década de 1970 que produziu, recordemo-lo de passagem, o fim da convertibilidade dólar-ouro, que marcara o período pós-II Guerra Mundial. Trata-se de factos obviamente conexos, sendo necessários juntá-los (e cotejá-los depois com a atualidade) para poder produzir juízos acertados sobre a situação mundial. O domínio global dos países ocidentais, ameaçado naquela altura, restabeleceu-se e consolidou-se depois por mais umas décadas, entre outros fatores devido à experiência politicamente vantajosa, embora economicamente desastrosa, que foi o apogeu neoliberal, seguido da "transição para o mercado" da Europa de Leste, o fim da União Soviética, o empobrecimento massivo e, em geral, o enorme colapso civilizacional daqueles países durante a década de 1990 e a viragem de século. Estes factos, registemo-lo bem, mesmo tendo implicado verdadeiras devastações económicas (Katastroika afigura-se realmente um nome muito apropriado para designar o processo), ou precisamente por isso, foram superlativamente aproveitados pelas elites ocidentais no sentido da imposição simultânea duma reforçada disciplina salarial às suas/ nossas populações e dum reforço generalizado de sentimentos de xenofobia, parcialmente induzido pelos próprios movimentos migratórios descontrolados provocados pelo afundamento das economias de Leste: incluindo trabalhadores muito qualificados que foram todavia obrigados a aceitar trabalhos desqualificados e muito mal pagos, conflituando aliás diretamente com os segmentos análogos das populações 'nativas'. A emergência da figura do Polish plumber, academicamente formado em engenharia mas com um emprego fazendo dele um blue collar, expressou e ao mesmo tempo causou (e ainda causa), quer no leste quer no oeste europeus, disfunções sociais de variadíssima ordem, que não cabe aqui analisar.

O resultado geral, porém, parece ter uma tonalidade identificável com enfraquecimento do estado social, pressões para a descida dos salários e maior desigualdade, erosão moral muito séria e muito generalizada, os sentimentos de xenofobia e a correlativa emergência política das direitas "étnicas" sendo realidades merecedores de consideração atenta. Esta configuração social, já de si muito problemática, tem por outro lado sido agravada mais recentemente com a chegada de novas vagas de imigrantes e refugiados, não raro provenientes de países sofrendo state failures induzidas por conflitos políticos promovidos pelas potências ocidentais, ou mesmo resultado de diretas intervenções militares ocidentais (Afeganistão, Iraque, Ucrânia, Síria, Líbia...).

Face a tudo isto, várias distinções se impõem de imediato. As intervenções militares ocidentais não são de todo um facto natural, embora evidentemente sejam muitíssimo delapidadoras de recursos naturais e enormemente poluidoras. A convergência a longo prazo da China, da Rússia e dos países do "terceiro 
mundo" com os padrões ocidentais não apenas é política e moralmente justificável, como é perfeitamente possível e tem largamente sido tornada uma realidade, sobretudo em virtude da moderna emergência da China e do enorme 'cone de sucção' que esse facto cria e que vários outros países (sobretudo países pobres) têm aproveitado, em ambiente genericamente de vantagens recíprocas. Nada disto, sublinhe-se, implica fim do crescimento económico, menos ainda decrescimento, mesmo nos países mais ricos; apenas ritmos mais lentos para estes do que os do "resto do mundo", e num contexto de enriquecimento global. Este último, pelo seu lado, não causa necessariamente problemas de excesso demográfico, bem pelo contrário: o próprio desenvolvimento socioeconómico tem induzido a cessação do crescimento demográfico, o que aliás pode também constituir um problema (envelhecimento excessivo), mas de natureza oposta. O fenómeno das migrações pode perfeitamente ser usado para, conjunturalmente, compensar estes desequilíbrios. Nada aí existe de tragicamente inultrapassável. Mais amplamente: não é possível, procedendo de forma lógica, argumentar em simultâneo de maneira malthusiana 'clássica', alegando que há população jovem a mais, e dizer que os sistemas de segurança social são insustentáveis, porque a população está demasiado envelhecida (e há portanto jovens a menos). Pode-se apresentar uma queixa ou outra, mas não se pode, em obediência aos ditames da lógica, argumentar com as duas em simultâneo. Todavia, isso acontece muito frequentemente, o que já de si constitui um facto sem dúvida interessantíssimo, a apelar a um esforço de investigação muito sério por parte da sociologia das mentalidades...

Adicionalmente, um maior desenvolvimento socioeconómico (seja este medido através da norma do PIB por habitante ou pelos chamados "indicadores sociais" ou de "desenvolvimento humano", critérios nem sempre sobrepostos ou sequer positivamente correlacionados) não produz necessariamente mais poluição, nem sequer maiores gastos energéticos. A título de exemplo: dois países de níveis de riqueza muito aproximados podem recorrer um deles sobretudo ao transporte individual, o outro ao transporte público, para resolver os seus problemas de mobilidade. No primeiro caso, tudo o mais permanecendo igual, o PIB por habitante será maior (porque há mais transações comerciais), mas a qualidade de vida será provavelmente menor; e os gastos energéticos serão evidentemente maiores. São sobretudo problemas deste tipo que devemos defrontar, e defrontar mesmo muito seriamente. Têm muitíssimo a ver com o nosso universo cultural e com vieses ideológicos, como é óbvio; e também muito a ver com os níveis de desigualdades em cada país e com o grau (e também o tipo) de intervenção económica estatal.

Tudo assuntos, já se vê, para considerar com gravidade nos nossos debates políticos, sobretudo ao nível em que a democracia realmente se exerce: o nível do estado-nação; e também plenamente dignos de serem trazido para o plano das relações internacionais, sem dúvida. Aliás, a reativação da democracia sob a forma de reativação das ideias de soberania e autodeterminação deve ela própria ser objeto duma consideração bem mais atenta, desde logo atinente às categorias de 
desenvolvimento político e de "desenvolvimento enquanto capacidades" (capabilities), de acordo com a fórmula famosamente sugerida por Amartya Sen (1987, 2001). Mais desenvolvida (politicamente, mas não só) é a sociedade politicamente organizada que mais consegue promover a realização das capacidades dos seus cidadãos, é claro; mas também a sociedade que mais se afirma enquanto realização das suas capacidades coletivas, demandando o correspondente reconhecimento no plano internacional. O que significa desde logo, por exemplo, que uma "globalização" entendida como (e performativamente transformada em) conjunto de constrangimentos inultrapassáveis é uma globalização que se torna, por definição mesmo, em fonte de subdesenvolvimento, ou desenvolvimento bloqueado, quer à escala dessa sociedade no seu conjunto, quer no que respeita aos membros desta.

Nada disso nos empurra, porém, para uma qualquer inevitabilidade de crescimento-zero, menos ainda de decrescimento. Aliás, experiências recentes de engenharia social, designadamente as correspondentes à chamada "austeridade", parecem sugerir sobretudo uma menor eficiência energética precisamente nesses períodos de empobrecimento coletivamente autoinfligido: nada garante, portanto, que por esse caminho resolvêssemos sequer os nossos problemas ecológicos. De forma simétrica, o mais recente crescimento autocentrado (em vez de export driven) da China tem tendido a transformar-se sobretudo naquilo que é habitualmente designado como "crescimento verde", com muito maior eficiência energética e redução ainda não, decerto, dos níveis de poluição, mas pelo menos do ritmo do seu crescimento.

De novo simetricamente, mas agora em recuo temporal: os habitantes da Inglaterra vitoriana lamentavam-se, e presumivelmente com muita razão, do insuportável cheiro a excrementos de animais que era trazido pela circulação muito intensa de veículos nas suas cidades. Em paralelo, os agricultores queixavam-se, por esse mundo fora, duma fertilidade cada vez menor das terras, o que, para além de fazer soar muitas 'campainhas' malthusianas, expressava a importante verdade de que muito daquilo que fora antes uma fonte secular de fertilidade dos terrenos (dejetos humanos e de animais domésticos) tinha deixado de o ser. Os agrónomos, compreensivelmente preocupados, afadigavam-se na procura de soluções: sobretudo o guano e os nitratos de sódio (ou "do Chile"), que foram paliativos insuficientes... até à síntese química da amónia, que resolveu o problema dos campos de forma bem mais consistente e duradoura, enquanto a tecnologia do motor de explosão permitia momentaneamente superar o das cidades.

Imagine-se o que seria, in illo tempore, fazer projeções de crescimento do PIB, da fertilidade das terras e dos níveis de produção de excrementos de animais de tiro urbanos, concluindo daí pela conveniência ou mesmo inevitabilidade do decrescimento económico, em nome simultaneamente de constrangimentos agrícolas e de imperativos olfativos... Talvez seja conveniente meditar nisso, na próxima vez que pretendermos estigmatizar a própria noção de crescimento económico, para já não falar da de desenvolvimento. Não será 
muito melhor, em vez disso, optar por qualificar aquelas categorias (como 'crescimento/desenvolvimento verde', crescimento/desenvolvimento autossustentável, etc.), em vez de as estigmatizar em bloco, ou no seu núcleo definidor?

\section{Referências bibliográficas}

ANIEVAS, Alexander \& Karem NISANCIOGLU (2015), How the West came to Rule - the Geopolitical Origins of Capitalism, London, Pluto Press.

ARRIGHI, Giovanni (1994), The Long Twentieth Century: Money, Power, and the Origins of Our Times, London, Verso.

ARRIGHI Giovanni (2009), Adam Smith in Beijing: Lineages of the Twenty-First Century, London, Verso.

BAIROCH, Paul (1999 [1993]), Mythes et Paradoxes de l'Histoire Économique, Paris, La Découverte/ Poche.

BLAUT, James M. (2000), Eight Eurocentric Historians, New York, The Guilford Press.

BOSE, Sugata \& Ayesha JALAL (2004), Modern South Asia - History, Culture, Political Economy, New York, NY \& London, UK, Routledge.

BOSE, Sugata (2006), A Hundread Horizons - The Indian Ocean in the Age of Global Empire, Cambridge, Massachusetts \& London, England, Harvard University Press.

BRAUDEL, Fernand (1979), Civilisation Matérielle, Économie et Capitalisme, XVe-XVIIIe Siècle. Paris, Armand Colin, 3 vols.

CANFORA, Luciano (2006), Democracy in Europe: A History of an Ideology (S. Jones, Trans.). Malden-MA, Oxford-UK \& Carlton-Victoria-Australia, Blackwell Publishing.

CONDORCET, Marie-Jean Antoine Nicolas de Caritat (1794-95), Esquisse d'un Tableau Historique des Progrès de l'Esprit Humain. Paris: Agasse. URL: https://tinyurl.com/y77ls9qu

DIAMOND, Jared (1999), Guns, Germs and Steel - The Fates of Human Societies, New York \& London, W. W. Norton \& Company.

DIAMOND, Jared (2007), Colapso - Como as Sociedades Escolhem o Fracasso ou o Sucesso, São Paulo \& Rio de Janeiro, Editora Record.

FERGUSON, Niall (2008), "Niall Ferguson Says U.S.-China Cooperation Is Critical to Global Economic Health", Washington Post, Monday, November 17. URL: https://www.washingtonpost.com/wp-dyn/content/article/2008/11/16/AR2008111601736.html

FONSECA, Pedro Cezar Dutra (2000), "As Origens e as Vertentes Formadoras do Pensamento Cepalino", Revista Brasileira de Economia, 54 (3), Julho/Setembro, pp. 333-358. URL: http://www.scielo.br/ scielo.php?script=sci_arttext\&pid=S0034-71402000000300004

GEORGESCU-ROEGEN, Nicholas (1995), La Décroissance - Entropie, Économie, Écologie, Paris, Sang de la Terre.

GEORGESCU-ROEGEN, Nicholas (1999), The Entropy Law and the Economic Process, Lincoln, iUniverse.com.

GERSCHENKRON, Alexander (1962), Economic Backwardness in Historical Perspective: A Book of Essays, Cambridge, Massachusetts, Belknap Press of Harvard University Press.

GRAÇA, João Carlos (2008), "Recepções de Malthus no Portugal de Oitocentos", Ler História, 54, pp. 163-199. URL: http://journals.openedition.org/lerhistoria/2411; DOI: https://doi.org/10.4000/ lerhistoria. 2411

HOBSBAWM, Eric (1989 [1987]), The Age of Empire, 1875-1914, New York, Vintage Books.

HOBSON, John M. (2004), The Eastern Origins of Western Civilization, Cambridge, UK, Cambridge University Press.

HOFFMAN, Philip (2015), Why Did Europe Conquer the World?, Princeton, NJ \& Oxford, UK, Princeton University Press. 
HOSELITZ, Bert (1962), Aspectos Sociológicos del Desarrollo,Barcelona, Editorial Hispano Europea. HUNTINGTON, Samuel (1968), Political Order in Changing Societies, New Haven, NY \& London, UK, Yale University Press.

LOEWEN, James W. (2007), Lies my Teacher Told to Me - Everything your American History Textbook Got Wrong, New York/London, The New Press.

MADDISON, Angus (2007), Contours of the World Economy 1-2030, Oxford, Oxford University Press.

MALTHUS, Thomas Robert (1980 [1798]), Ensaio sobre o Princípio da População, Lisboa, Publicações Europa-América.

MARSHALL, Thomas Humphrey (1950), Citizenship and Social Class and Other Essays, Cambridge, Cambridge University Press.

MARX, Karl (2012 [1867]), Capital, Vol. 1: A Critique of Political Economy (Samuel Moore and Edward Aveling Trans.), Dover, Courier Corporation.

MARX, Karl \& Friedrich ENGELS (1969 [1848]), Manifesto of the Communist Party, In Marx/Engels Selected Works, Vol. 1, Moscow: Progress Publishers. URL: https://www.marxists.org/archive/ marx/works/download/pdf/Manifesto.pdf

MAYER, Arno J. (1981), The Persistence of the Old Regime: Europe to the Great War, New York, Pantheon Books.

MORRIS, Ian (2011), Why the West Rules (For Now) - The Patterns of History and What They Reveal about the Future, London, Profile Books.

PAUWELS, Jacques R. (2002), The Myth of the Good War: America in the Second World War, Toronto, James Lorimer Limited Publishers.

PAUWELS Jacques R. (2014), 1914-1918, La Grande Guerre des Classes (traduit du néerlandais par Frank Degrez), Bruxelles, Les Éditions Aden/L'Imprévu.

POMERANZ, Kenneth (2000), The Great Divergence - China, Europe, and the Making of the Modern World Economy, Princeton, NJ \& Oxford, UK, Princeton University Press.

ROSTOW, Walt Whitman (1960), The Stages of Economic Growth: A Non-Communist Manifesto, Cambridge, Cambridge University Press.

SEN, Amartya (1987), Commodities and Capabilities, New Delhi, Oxford University Press.

SEN, Amartya (2001), Development as Freedom, Oxford, Oxford University Press.

SMITH, Adam (1999 [1776]), The Wealth of Nations, London, Penguin.

STREECK, Wolfgang (2016), "Heller, Schmitt and the Euro", in W. Streeck, How Will Capitalism End: Essays on a Failing System, Brooklyn, NY, Verso, pp. 151-163. 